\title{
ACHIEVING BOTH CREATIVITY AND RATIONALE: REUSE IN DESIGN WITH IMAGES AND CLAIMS
}

\author{
D. Scott McCrickard \\ Center for Human-Computer Interaction \\ Virginia Tech \\ USA \\ Stacy M. Branham \\ Center for Human-Computer Interaction \\ Virginia Tech \\ USA
}

\author{
Shahtab Wahid \\ Center for Human-Computer Interaction \\ Virginia Tech \\ USA \\ Steve Harrison \\ Center for Human-Computer Interaction \\ Virginia Tech \\ USA
}

\begin{abstract}
Although designers often try to create novel designs, many designs are based on previous work. In this paper we argue for the reuse of rationale, in the form of claims, as a central activity in design, and explore how this can be used to inspire creativity. We present a design activity in which images and claims are reused to create a storyboard and illustrate how creativity and rationale complement each other. Our work serves to demonstrate that an appropriate design activity can be used to leverage creativity with the use of rationale.
\end{abstract}

Keywords: reuse, creativity, rationale, claims, images.

\section{INTRODUCTION}

The formal and mechanized nature of many design rationale methods may seem a hindrance to the creative process, inhibiting the natural flow of ideas that is so important to groundbreaking concepts. However, by ignoring the lessons learned by others, a designer may risk lacking the knowledge to put forward potentially creative ideas. In this paper we explore ways to present design rationale that help stimulate the creative process, while providing at the appropriate time a bridge to design rationale. In particular, we consider how the representation of images - a familiar construct in many creative activities - encourages designers to generate novel ideas as a first instinct, with the rationale enabling the desire to justify, compare, and build toward a solution.

One important approach to leveraging design rationale is appropriate knowledge reuse, wherein previously created artifacts are considered in the design process toward creating a design that might be an improvement over a prior solution. Many practitioners exercise

(C) 2011 D. Scott McCrickard, Shahtab Wahid, Stacy M. Branham, and Steve Harrison, and the Agora Center, University of Jyväskylä

URN:NBN:fi:jyu-2011081711241 
knowledge reuse informally by basing new solutions on old experiences: Products developed previously could be used in new ways, distinct ideas can be connected together, or evolutions of previous products can be made possible through technological advances. When new products are created, designers tend to naturally reuse techniques of the past-providing impetus behind an often-ignored need to gain and even build on what has been used before (Whittaker, Terveen, \& Nardi, 2000).

New designs built with formal design rationale approaches show promise in enabling designers to think deeply about the trade-offs presented in each design decision towards lowering costs (Bias \& Mayhew, 2005) and improving usability (Wania, 2008). Prior efforts within interface development communities have investigated ways of facilitating the reuse of various components, often rooted in design knowledge capture (Borchers, 2000; Hughes, 2007; Landay \& Borriello, 2003; Sutcliffe \& Carroll, 2000). However, constraints placed in design rationale systems, such as formalized structures and processes, can hamper the effectiveness of creative workers (Horner \& Atwood, 2006).

Creative ideation is often seen as beneficial since it can spark new directions with the potential to lead to interesting and novel designs. Quality creative ideas balance novelty with appropriateness (Amabile et al., 1996; Bias \& Mayhew, 2005), often with a role for appropriate information acquisition and selection. Even though there are many avenues to creative design, it is essential to consider how well the generated ideas fit with the intended design.

In this paper, we put forth the position that those engaged in design may benefit from both creative ideation and rationale-based reasoning centered around reusable features. Although new ideas might lead to fresh ways of thinking about technology, we believe that their value may be increased when grounded in reasoning acquired through previous efforts. Creativity and rationale are not, a priori, opposing forces, but rather could be made complementary when encapsulated in appropriate design artifacts. We reason that lightweight rationale buffered by rich pictures and an engaging storyboarding activity may be one solution to this challenge.

Therefore, we explore the role of creativity and rationale in reuse with emphasis on the claim - a form of rationale capturing a feature and its design trade-offs (Carroll \& Kellogg, 1989). We articulate the advantages of leveraging rationale, but also acknowledge the need to ease its reuse in design. Thus, we investigate the nature of creativity, leading to the role that imagery can carry out in aiding claims reuse. In an effort to further explore this space, we created domain-specific cards that merge imagery and claims together. We also present one technique, a design activity in which these cards are used to construct storyboards, and reflect on the role of creativity and rationale during reuse.

\section{RATIONALE AND REUSE}

When practitioners approach design problems in search for answers, they rely on internalized reasoning as well as the reuse of past experiences and solutions. Formal rationale reuse methods try to mimic and improve upon these aspects of design with more explicit, externalized representations of knowledge. As digital or physical artifacts, reusable design rationale units provide focus points for dialectic collaboration and offer generalized solutions for contextualized consideration. Moreover, they open opportunities for design knowledge to traverse the gap of time and space between teacher and pupil, or between peers with different perspectives. 
History includes many methods for capturing and associating knowledge, toward making it more accessible to researchers. As stores of knowledge grew in the early part of the $20^{\text {th }}$ century, visionaries like Paul Otlet (Wright, 2007) and Vannevar Bush (1945) presented grand schemes for capturing, linking, and accessing knowledge. Their focus was not merely on classifying collections of books, but on identifying the core knowledge units within them that appropriately capture the essence of the contribution.

Design rationale emerged from the inherent bounded rationality of design thinking and wicked nature of design problems (Rittel \& Webber, 1973; Simon, 1996). These notions were encapsulated in the issue-based information system (IBIS) model of design argumentation, which structures discourse by design topic, issues, arguments, and questions of fact that are raised in design dialogue (Kuntz \& Rittel, 1970). MacLean, Young, Bellotti, and Moran's (1991) questions, options, and criteria (QOC) presents a more formal design rationale model, encompassing questions about the design space, alternative design options, and criteria for selecting the solution. In a less formal representation, case studies capture the key rationale that results in observed design outcomes (Borchers, 2000; Harvard Business School, n.d.).

Perhaps the component most commonly associated with reuse in interface design is the pattern (Borchers, 2000; Landay \& Borriello, 2003; Lin \& Landay, 2008; van Duyne, Landay, \& Hong, 2007; Yahoo! Developer Network, n.d.). Originally proposed by Alexander, Isikawa, and Silverstein (1979) for the design of buildings and towns, patterns are reusable design knowledge components. They include information such as context of use, conflicting forces, and potential solutions - components that incorporate design rationale. Prepatterns are forms of patterns used in emerging design domains (Saponas, Prabaker, Abowd, \& Landay, 2006).

Similar to the pattern or case study, but of a different scale, is the claim. First introduced by Carroll and Kellogg (1989), claims document the psychological effects of user interface features in context. Although claims were initially proposed as disposable knowledge units (e.g., Carroll \& Kellogg, 1989; Rosson \& Carroll, 2002), they have since been identified to be of appropriate granularity for reuse (Payne, Allgood, Chewar, Holbrook, \& McCrickard, 2003; Sutcliffe \& Carroll, 2000). Through these transitions, the claim has taken on differing shapes and sizes. In this paper, we focus on its simplest form: a feature coupled with usability trade-offs (Figure 1).

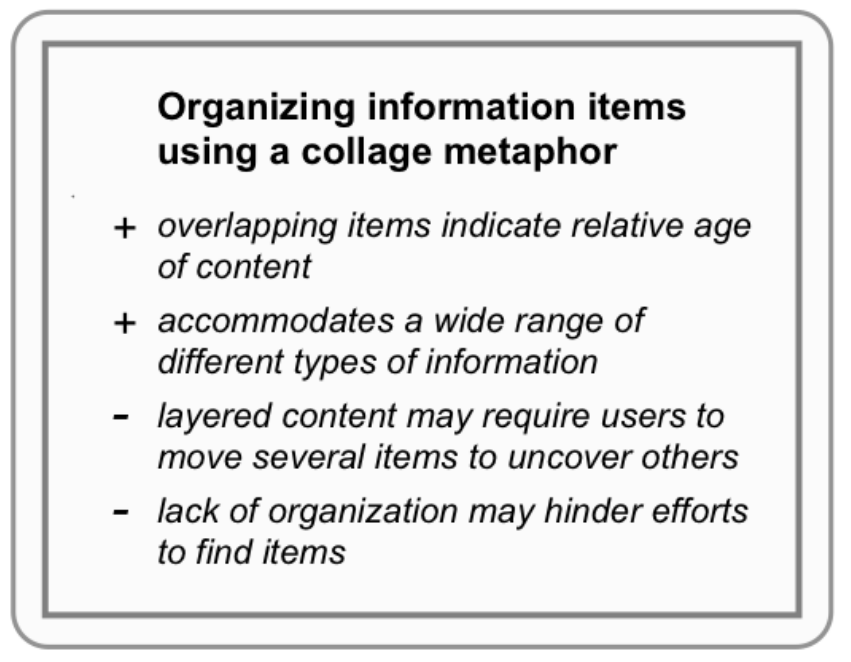

Figure 1. An example claim with a feature, upsides, and downsides. 
Some claims, as illustrated by our example in Figure 1, are based upon scientific findings (Greenberg \& Rounding, 2001). Others may be generated by designers based upon experience or intuition. The contextualized nature of a claim's creation may alter the relevance and meaning of upsides and downsides when claims are reused in new design situations. Although these characteristics may result in varying claim quality, there is an important contribution beyond explicit transfer of design knowledge. Claims motivate design reasoning, particularly because they call attention to trade-offs and encourage designers to increase positive impacts (Rosson \& Carroll, 2002). In addition, claims documented by one designer in a unique design situation may provide an outsider's perspective to future designers that interact with that claim. Claims, then, are not just about an explicit hand-off of expert knowledge; they are instead about designer engagement with external perspectives in a user-centered, trade-offs-oriented mindset.

Claims, like patterns, are discrete units of design knowledge. One salient departure is the structure and depth of information captured in each rationale unit. Where a single pattern may fill a dozen pages (van Duyne et al., 2007) and consist of many different parts, such as a synopsis, background, problem, solution, forces, and evidence (Saponas et al., 2006), a claim in its basic form encapsulates a feature description with its design trade-offs (Rosson \& Carroll, 2002). Although we acknowledge patterns can emerge in different sizes, we submit claims as a viable alternative to patterns since their difference in structure may make claims designer digestible — quick to read, comprehend, and act upon (Carroll \& Kellogg, 1989).

Claims may be informally and quickly drawn up in the heat of design situations with minimal interruption to design activities. Of course, the test of whether or not designers actually capitalize on this opportunity relies upon sufficient designer buy-in to design rationale reuse; we believe it can be achieved with the framing of an appropriate design activity. Hence, we find claims one suitable form of rationale because they have the potential to both provide insight at design prototyping time as well as capture lessons learned in situ that may be passed on to designers in different times, places, and contexts.

Although design rationale played a larger role earlier, it is now true that design rationale is not widely used (Carroll, 2003), in part because it is prone to capture, retrieval, and usage limitations during design (Horner \& Atwood, 2006). Keeping this in mind, we acknowledge that claims are also subject to potential negative consequences. When faced with a large collection of claims, it can be burdensome and time-consuming for designers to investigate claims because of their textual nature - necessitating quick recognition of the essence of claims. It is also quite possible that a designer might have a different view of the feature, but this may potentially influence or eliminate a designer's independent consideration of what the impact of the artifact might be and how it may be used. Designers need to think for themselves to further develop their own understanding of an artifact instead of immediately being exposed to the bias of the claim itself. Only then can a claim serve to challenge designers' own understanding of the artifact. Creating a claim can encourage designers to think for themselves and draw on their own experiences. However, a source of inspiration for new features that might go hand in hand with the existing claims would benefit designers greatly. A new way to represent claims that can inspire designers through creative means is needed to reduce the negative impact during reuse. 


\section{CREATIVITY SUPPORTING REUSE}

Creativity has long been a trait sought in design process - it is the source of new ideas, new products, and new hope for human discovery. And yet, researchers are still working to describe and explain the creativity phenomenon. Creative acts can even take on many different forms (Harrison \& Tatar, 2008). The result is a varied set of equivocal conceptions of creativity and an abundance of questions yet unanswered. Definitions of creativity range from the creative process (e.g., Amabile, 1983; Hogarth, 1980; Osborn, 1963; Shneiderman, 2000; Sonnenburg, 2004; Wallas, 1926), to the creative person (e.g., Guilford, 1950; Lubart, 2005), to the creative product (e.g., Amabile, 1982; Boden, 1994). As human-computer interaction (HCI) researchers, our concern with creativity is twofold: Not only are we deeply engaged with questions of how technology can enhance creative endeavors, but - and this second obligation often goes neglected - we also are invested in supporting creativity in our usability design processes. The latter of these is a key focus of this work.

There is a common misunderstanding about the definition of creative products: It is often assumed that creative products must only satisfy the singular criterion of novelty. Certainly, a creative idea must be new, at least to the immediate creators (Bias \& Mayhew, 2005), but that is not sufficient. Creative ideas must also exhibit appropriateness (Amabile et al., 1996). That is, the idea must solve a problem, be useful and usable, and otherwise satisfy measures of quality.

Generating creative ideas can be considered as the reuse of existing knowledge to elicit new knowledge: "Although cases of insight do occur, more often than not creative thought calls for information acquisition and the selection of appropriate concepts for understanding this information" (Mumford, 2000, p. 315). Furthermore, creativity is often the result of the fusion of existing knowledge from disparate domains: "Creative novelty springs largely from the rearrangement of existing knowledge - a rearrangement that is itself an addition to knowledge. Such rearrangement reveals an unsuspected kinship between 'facts long known but wrongly believed to be strangers to one another'" (Kneller, 1965, p. 4). Recombinations of existing knowledge can sometimes be viewed as crossing boundaries between fields to apply an analogous solution to a new problem (Thomas, Lee, \& Danis, 2002). These types of recombinations can sometimes be achieved through lateral thinking techniques, whereby diverse stimuli are used to initiate novel connections (De Bono, 1990).

Another important aspect of creativity is its temporal span; it is a staged process that can vary from moments to days in duration. One of the foundational models, conceived by Wallas (1926), includes the transition of an individual through four sequential phases: preparation, incubation, illumination, and verification. Preparation is marked by the gathering of existing information and domain knowledge in response to a motivating problem; it is a period during which the creator "reads, notes, discusses, questions, collects, explores" (Kneller, 1965, p. 48). During incubation, the knowledge gained through preparation is left to steep and the problem, perhaps, is even forgotten altogether. In a moment of unconsciously driven illumination, the creator happens upon a novel solution. In the final phase, verification, the implications of the speculative solution are consciously considered and revised for appropriateness. More recent constructions of the creative process (e.g., Amabile, 1983; Hogarth, 1980; Osborn, 1963; Shneiderman, 2000; Sonnenburg, 2004; Wallas, 1926) still include these foundational phases at an abstracted level. 
In this staged process, idea illumination and idea verification are separate phases and may take place one before the other (as formalized in Osborn's, 1963, brainstorming process). With respect to user-centered HCI design, we consider this an opportunity to balance images (i.e., rich stimuli that may aid idea generation) and reusable design rationale (i.e., a cognitive tool that may aid idea assessment) in a combined artifact-based activity. We propose that, by presenting images first, the initial focus will be placed on the creation of novel ideas without immediate attention to whether ideas fit both the novel and appropriate constraints. And, presenting rationale second may allow novel ideas to be explored before being reined in by rationale in the assessment of appropriateness. The next two sections explore reusable rationale and images, respectively, as complementary components for enabling the creative process.

Pictures, images, and sketches have been incorporated in a number of creative design activities for their ability to stimulate divergent thinking. In creative writing, pictures "sparks" are used to help inspire a new story direction (Kellaher, 1999). Trend cards, each comprising a short textual fact about a target market and related picture, are used in industry to stimulate brainstorming sessions (Smith, 2009). The Creative Whack Pack (von Oech, 2008) and the Thinkpak (Michalko, 2006) use sketches and images to encourage creative problem finding and problem reframing. Picture-based artifacts that promote creativity are also beginning to appear in HCI design methods in the form of product example pictures (Herring, Chang, Krantzler, \& Bailey, 2009) and cards that capture values (Nathan, Friedman, \& Hendry, 2009). Most existing image-centric creative design activities are strong on brainstorming and idea generation, but do not focus on issues of appropriateness and rationale.

In this paper, we consider images of system features or of symbols thereof not only because this fits the granularity of our chosen unit of design rationale, but also because features may be an appropriate unit for sparking creative ideation. We believe that pictures of system features — objects and symbols captured as moments in rich context — are evocative stimuli that may provide a platform for lateral thinking. This type of thinking spawns novel connections between stimuli-pictures of features - and the problem domain. Furthermore, a pool of diverse feature pictures spread out on a surface such that most are visible at the same time has potential to provide opportunities for novel recombination and rearrangement of existing ideas. Finally, because the visual nature of pictures allows them to be seen and understood in little more than an instant, it may allow designers to flow fluidly between ideas as they "read" each image, thus supporting the preparation and incubation stages of creative ideation.

\section{IMAGE AND CLAIM REUSE IN STORYBOARDING}

Storyboards are visual narratives that include actors engaging in a series of actions toward a common goal. Typically, they consist of multiple panels made of pictures and an accompanying narrative that illustrates a temporal progression. Key aspects of a storyboard are the portrayal of time, the inclusion of people and emotions, the inclusion of text, and the level of detail (Truong, Hayes, \& Abowd, 2006). Used by those involved in the creation of movies, cartoons, and commercials, they are powerful tools for thinking through and presenting the most important aspects of a narrative (Finch, 1973; Hart, 1999). 
In HCI, storyboards have been used in the design process to illustrate how users may interact with a system (Buxton, 2007; Sharp, Rogers, \& Preece, 2007). Primarily used in early prototyping phases, storyboards in this domain describe the user's interaction with a system over time through a series of graphical depictions, often sketches, and units of textual narrative. Storyboards have been used to help understand the flow of the interaction scenario, to eliminate costly elements of a design, and even to decide how to pitch ideas to others (Buxton, 2007; Rosson \& Carroll, 2002).

Reuse has been supported in the storyboarding process, both formally and informally. The earliest storyboards of films and cartoons used reusable components of characters (Finch, 1973). Storyboarding tools such as SILK (Landay \& Myers, 1995), DENIM (Newman, Lin, Hong, \& Landay, 2003), and DEMAIS (Bailey \& Konstan, 2003) facilitate storyboarding to create prototypes early in design and support reuse through cutting, copying, and pasting of images within and between storyboards. As in our process, the Damask storyboarding tool leverages the reuse of patterns, although the authors acknowledge that the size of many patterns made them difficult to understand (Lin \& Landay, 2008).

In our process, we seek to leverage and combine prior work in design rationale, creative inspiration through images, and storyboarding through an image-centric artifact set. Each artifact is presented in the form of a card depicting a feature through an image and label on the front and an associated claim on the back (see Figure 2). We chose to place representative images and brief titles on the front of each card with the expectation that artifacts would be quickly recognized and designers would gain inspiration from the artifacts. In so doing, we expect that they would first consider broad possibilities of how the artifact could be used in design before being influenced by the claim on the back. However, the claim could serve as a gateway to formal design rationale, encouraging designers to consider the validity of their ideas in light of the rationale.

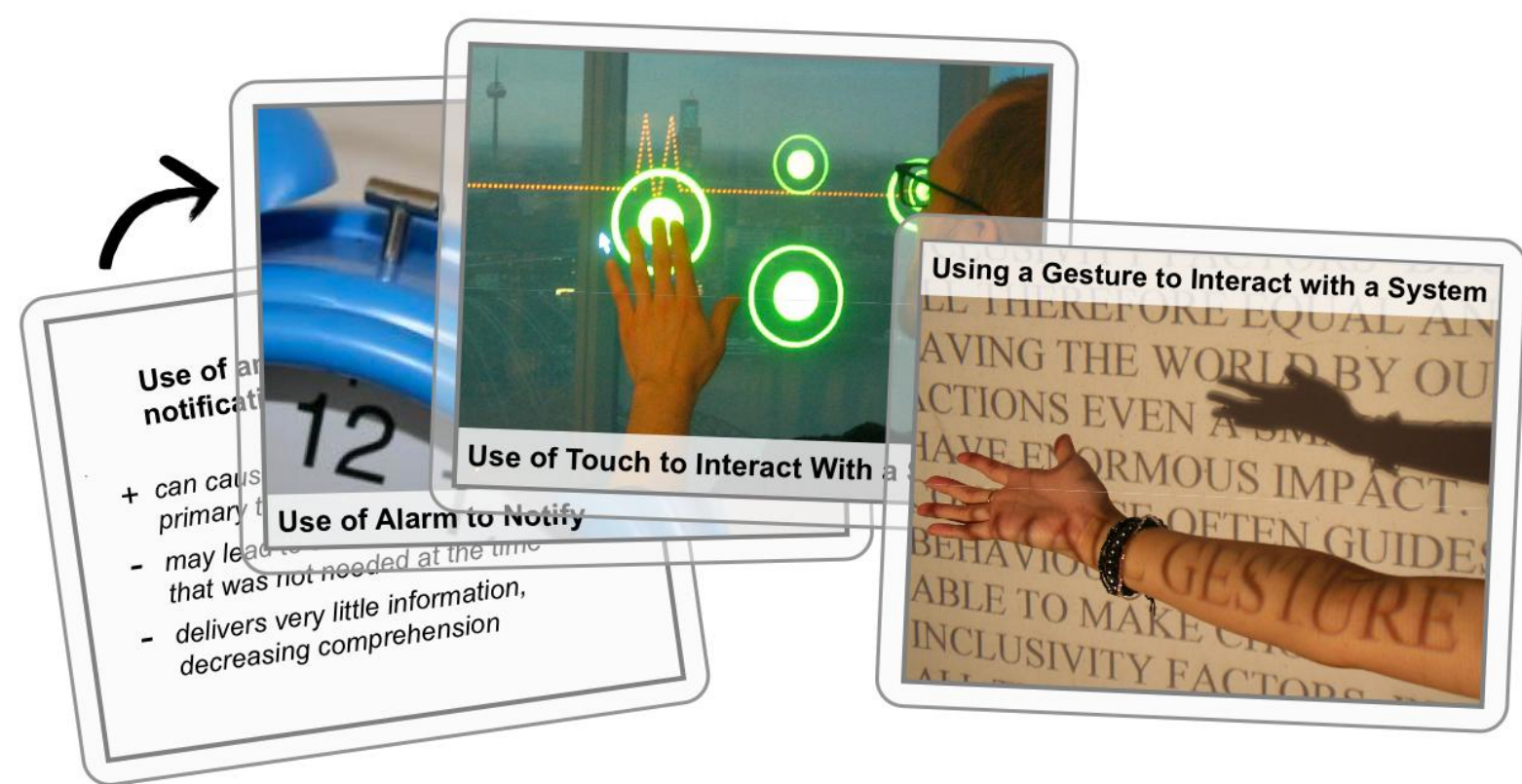

Figure 2. Card fronts have pictures with labels to represent features, and card backs present textual claims with user-centered trade-offs. 
To explore this area, we are developing a method to facilitate the creation of storyboards by reusing premade artifacts for the creation of notification systems, tools that allow users to monitor information in dual-task situations (McCrickard, Chewar, Somervell, \& Ndiwalana, 2003). Our initial work led us to investigate the use of these cards in design sessions, where we asked groups of three to utilize the artifacts in creating a prototype of a notification system (Wahid, Branham, Cairco, McCrickard, \& Harrison, 2009). Twenty-one graduate students were gathered to take part in seven sessions for the study. In each design session, the participants were presented with one unique problem and asked to create an appropriate notification system. Some of the design problems we assigned involved notifying nuclear plant operators of changing core temperatures, passengers in airports of flight status changes, commuters of empty parking lot spots while driving, theme park visitors of ride wait times, and students of empty spots for classes they wish to register for.

All participants were actively engaged in conducting HCI research or enrolled in a graduate HCI course at the time of the study. Their familiarity with storyboarding and claims varied. Because we target our artifacts to novice designers as well, we preferred to recruit novice designers at this stage of our investigation. Here, we report on our observations of the balance of creativity and rationale centered about the cards.

Novice designers engaged in this design activity work to familiarize themselves with the set of cards, decide on what cards might be useful for the system they wish to prototype, and construct a storyboard by placing cards together. When needed, they created their own cards to incorporate new ideas. Our observations of this activity have allowed us to understand better how these cards are able to encourage designers to balance novel ideation and grounded reasoning. We provide below some examples from design sessions we ran showing how these cards impacted the construction of storyboards and provided opportunity for creative ideas along the way.

The use of imagery proves to be an important segment of the activity since it is a springboard for new ideas. One way in which imagery does this is by making ideas ready at hand. It enables quick digestion and recognition of reusable ideas, so much so that designers often find themselves considering all of the cards as potential candidates for their designsomething often not the case when features must be read in the form of plain text. By making more features available to designers for ready consideration, we vastly expand the design space considered for assimilation in a design session. The pictures support, to a degree, universally understood communication of its direct message, the feature, and provide designers the space to incorporate the appropriate cards into their storyboard.

On the other hand, pictures also support different messages and interpretations of their contents. This proves to be another advantage of using imagery: inspiring the designers to think of other artifacts that might not have been considered, potentially leading to novel ideas. In many of our design sessions, we observed participants thinking of new ideas while viewing the images that were unrelated to the nature of the artifact the image presented. For example, we observed a group that reinterpreted a card about relating preexisting user knowledge to a notification generated by a system. The image used for this card was a picture of a chat window showing the chat history. A participant in the group looking at the card chose to focus on the message timestamp that was contained within the chat window and proposed that the timestamp be a feature incorporated into their storyboard. The timestamp happened to be a part of the image, but was not necessarily there to illustrate the idea of the 
card. This serves to demonstrate that images can potentially inspire ideas that are beyond that of the claims themselves, leading to creative, divergent thinking patterns as well as a new source of knowledge to capture and store.

Images also afforded a platform for idea combination and domain transcendence-both tenets of creativity. Being that the pictures - which were taken in diverse times and placesall came together on a single table top, unique comparisons and couplings became possible and even natural. Participants placed pictures side by side for comparison and on top of one another for combination. As an example of feature combination, one group discussed joining a large-screen public display with a peripheral display to create a less distracting and userdriven source of information. Although the features we presented to participants were of the same domain (notification systems), we believe that there is promise in presenting an even more diverse set of images to designers to enable novel combinations.

The textual claims on the back of the cards serve as important ways for designers to consider the utility of the reusable ideas and to gauge how appropriate they are. Whenever designers need more information or have doubts about how to use an artifact, claims serve as a way of describing the artifact and its utility. The claim trade-offs play a vital role in allowing designers to decide whether the artifact should be used in a design. Designers turn to the textual claim when debating the impact of a feature - especially high-impact negative ones that they may not have realized. In one instance, we observed a designer become aware of a claim's downside articulating that a notification generated by the system might be missed by the user. The designer immediately found another card that might mitigate the effects of this downside. Claim trade-offs also aid in deciding between cards when alternatives present themselves. The advantage in having the textual claim is that it can provide designers with rationale-based design concerns that they have possibly not thought of to challenge or counter their own interpretation of the card-providing an alternative perspective to the consideration of the card. Ultimately, the presence of textual claim information makes the designers more aware of the need to consider carefully the reasons for including a feature in a design.

Creating new cards to capture new ideas in the form of pictures and claims is also an important part of the activity. In the sessions we ran, three new cards were created. Although we found that cards are often created as a result of an idea that was inspired by another card, it would be hard to identify whether it is solely because of the image or whether the associated claim played a role as well. For instance, a group decided to create a new card based on a card about graphical information because they wanted to create a system that also incorporated geospatial location, and therefore created a new card about geospatial representation of information. The group drew a picture of a map with various points of interest within it and created a claim that was largely a more specified version of the claim used for graphical information. Their need to refer to the other card demonstrated that they wanted to maintain the same level of scope, making it generic and trying not to overspecify the card so that its potential reuse would not be restricted. Thus, the authoring of the claim was influenced by the claims that were already around them. Although we see that new ideas can arise, we notice that these ideas are often grounded in other artifacts that inspired the designers. Even though creative thought inspired by the graphical information imagery provided a springboard for knowledge capture, the rationale ensured the designers considered the consequence of the new feature. The burdens of creating a new card in terms of content might have been lowered by introducing a 
simple card structure, but we noticed that other factors, such as the designers' own knowledge and confidence in themselves, influenced whether a card was created.

Ultimately, the storyboard is constructed by choosing relevant cards, sequencing them according to a determined task flow, and then writing an accompanying narrative or scenario for each segment of the storyboard to solve the given design problem (see Figure 3). We acknowledge the final product of this activity is not a traditional storyboard since it does not enforce sketching. However, elements such as actors and the portrayal of time are still embodied within the narrative.

The construction process is also a careful interplay between creativity and rationale. Designers engage in exploring new ways to combine and order cards to create new functionality. For example, a new notification method could be created by combining a card about a blinking light with an audio notification card-leading them to either place the cards side by side or on top of each other. At the same time, their combined use is analyzed through the claims and further discussion on its potential effects. It is important to note that designers go beyond the individual cards and also focus on the system as a whole - testing out creative new task flows that result from a new sequence of artifacts. Although the participants chose the cards they felt were relevant to their goals, further investigation would be needed to understand which cards are prioritized depending on the given design problems and the eventual quality of the storyboards.

We believe that the nature of combined imagery and rationale is a primary factor in facilitating designers in brainstorming and considering consequences at the same time. Reusing ideas of the past may be beneficial, but the application of these ideas in new ways and forms may bring out potentially innovative solutions.

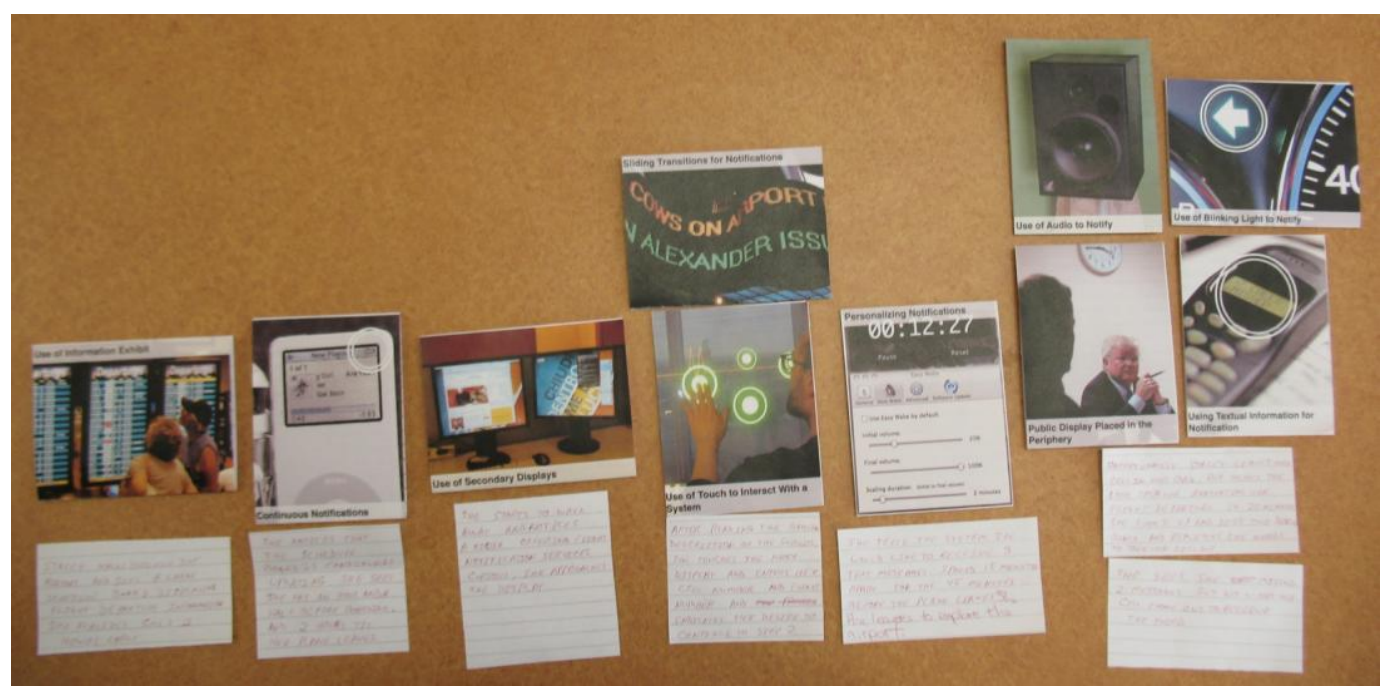

Figure 3. An example of a storyboard created by reusing the cards. The narrative serves to bring context and integrate the cards together.

\section{CONCLUSIONS}

Supporting reuse is an important step in bringing together creativity and rationale. To support the types of creative sparks we observed, a corpus of rationale is needed so that there can be a 
ready source of inspiration and a variety of creative ways of combining them. We acknowledge that identifying new rationale can be beneficial, but believe that a preexisting, reusable set, especially at the start of a project, can serve these goals more effectively.

Even if reuse were to be supported, one could perceive that reuse, as a central tenet to design, can lead to uncreative and uninspired outcomes. However, this perception may be changed with the incorporation of mechanisms that inspire creative thought. In working toward this goal, careful thought must be put into the design of the reusable artifact and how those artifacts might interact with each other because that is where the creativity will most likely percolate. Although further investigation of our technique is needed, the combination of rationale and creativity for reuse seems to be a step toward provoking designers into creating innovative solutions and create a fresh source of knowledge that can be stored for others to reuse later.

Putting such a vision into practice requires that we identify appropriate mechanisms to capture rationale, inspire creativity, and construct meaningful prototypes. Claims are uniquely structured to capture knowledge in a designer-digestible manner to support reuse, and appropriate images associated with the claims summarize the message while facilitating ideation and reinterpretation. Because of their structure, they can be authored easily with limited effort — reducing the burdens associated with formal capture of rationale.

These knowledge-capture and presentation mechanisms (claims and images) must come together through a meaningful design activity. In our case the activity happens to be storyboarding, but other prototyping activities might prove to be equally useful. Because storyboarding is a creative and fun way to illustrate both visually and textually the task flow of a new system, it leverages both the visual images through early innovative bursts while encouraging deeper reflection in the authoring of accompanying text. Designers perform the early creative stages in their design by identifying options, then exploring and conceptualizing solutions - but the claims provide a basis for scientifically sound solution verification and production.

At this point, this work is taking steps to set the stage for design by reuse by assessing the benefits of incorporating creativity and rationale together. One future direction is to assess the quality of the designs that are produced as a result of the activity. Another future effort must explore how the process of brainstorming before storyboard construction can be improved through appropriate designer exposure to images and claims. Early exposure to images without rationale might inspire designers to interpret the images in very different ways, leading to a larger pool of possible insights. When designers are exposed to the associated rationale later, they may weigh the utility of their ideas against the recorded argumentation.

\section{REFERENCES}

Alexander, C., Isikawa, S., \& Silverstein, M. (1979). A pattern language: Towns, buildings, construction. New York: Oxford University Press.

Amabile, T. M. (1982). The social psychology of creativity: A consensual assessment technique. Journal of Personality and Social Psychology, 43, 997-1013.

Amabile, T. M. (1983). The social psychology of creativity: A componential conceptualization. Journal of Personality and Social Psychology, 45, 357-376. 
Amabile, T. M., Collins, M. A., Conti, R., Phillips, E., Picariello, M., Ruscio, J., \& Whitney, D. (1996). Creativity in context: Update to the social psychology of creativity. Boulder, CO, USA: Westview Press.

Bailey, B., \& Konstan, J. A. (2003). Are informal tools better? Comparing DEMAIS, pencil and paper, and authorware for early multimedia design. In Proceedings of the 2003 SIGCHI Conference on Human Factors in Computing Systems (CHI '03; pp. 313-320). New York: ACM Press.

Bias, R. G., \& Mayhew, D. J. (2005). Cost-justifying usability. San Francisco: Morgan Kaufmann.

Boden, M. A. (1994). Dimensions of creativity. Cambridge MA, USA: MIT Press.

Borchers, J. O. (2000). A pattern approach to interaction design. In Proceedings of the Conference on Designing Interactive Systems (DIS '00; pp. 369-378). New York: ACM Press.

Bush, V. (1945). As we may think. The Atlantic Monthly, 176(1), 101-108.

Buxton, B. (2007). Sketching user experiences: Getting the design right and the right design. San Francisco: Morgan Kaufmann.

Carroll, J. M. (2003). HCI models, theories, and frameworks: Toward a multidisciplinary science. San Francisco: Morgan Kaufmann.

Carroll, J. M., \& Kellogg, W. A. (1989). Artifact as theory-nexus: Hermeneutics meets theory-based design. In Proceedings of the 1989 SIGCHI Conference on Human Factors in Computing Systems (CHI '89; pp. 714). New York: ACM Press.

De Bono, E. (1990). Lateral thinking. Hammondsworth, England: Penguin Books.

Finch, C. (1973). The art of Walt Disney: From Mickey Mouse to the Magic Kingdom. New York: Harry Abrams.

Greenberg, S., \& Rounding, M. (2001). The notification collage: Posting information to public and personal displays. In Proceedings of the 2001 SIGCHI Conference on Human Factors in Computing Systems (CHI '01; pp. 514-521). New York: ACM Press.

Guilford, J. (1950). Creativity. American Psychologist, 5, 444-454.

Harrison, S., \& Tatar, D. (2008, June). "It's just a rationale!”: Creativity in the formation and application of design rationale. Paper presented at the Workshop on Creativity and Rationale in Software Design, University Park, PA, USA.

Hart, J. (1999). The art of the storyboard: Storyboarding for film, TV, and animation. Amsterdam: Focal Press.

Harvard Business School (n.d.). Faculty \& research cases. Retrieved August 4, 2011 from http://www.hbs.edu/research/publications/cases.html

Herring, S. R., Chang, C. C., Krantzler, J., \& Bailey, B. P. (2009). Getting inspired! Understanding how and why examples are used in creative design practice. In Proceedings of the 2009 SIGCHI Conference on Human Factors in Computing Systems (CHI '09; pp. 87-96). New York: ACM Press.

Hogarth, R. M. (1980). Judgement and choice: The psychology of decision. Chichester, UK: John Wiley \& Sons.

Horner, J., \& Atwood, M. E. (2006). Design rationale: Rationale and the barriers. In Proceedings of the Nordic Conference on Human-Computer Interaction (NordiCHI '06; pp. 341-350). New York: ACM Press.

Hughes, M. (2007). A pattern language for user assistance. interactions, 14(1), 27-29.

Kellaher, K. (1999). 101 picture prompts to spark super writing: Photographs, cartoons, art masterpieces to intrigue, amuse, inspire every writer in your class. New York: Scholastic Professional Books.

Kneller, G. F. (1965). The art and science of creativity. New York: Holt, Rinehart and Winston.

Kuntz, W. R., \& Rittel, H. W. J. (1970). Issues as elements of information systems (Tech. Rep. No. 131). Berkeley, CA, USA: Institute of Urban and Regional Development, University of California.

Landay, J. A., \& Borriello, G. (2003). Design patterns for ubiquitous computing, IEEE Computer, 36(8), 93-95.

Landay, J. A., \& Myers, B. A. (1995). Interactive sketching for the early stages of user interface design. In Proceedings of the 1995 SIGCHI Conference on Human Factors in Computing Systems (CHI '95; pp. 4350). New York: ACM Press. 
Lin, J., \& Landay, J. A. (2008). Employing patterns and layers for early-stage design and prototyping of crossdevice user interfaces. In Proceedings of the 2008 SIGCHI Conference on Human Factors in Computing Systems (CHI '08; pp. 1313-1322). New York: ACM Press.

Lubart, T. (2005). How can computers be partners in the creative process: Classification and commentary on the special issue. International Journal of Human-Computer Studies, 63, 365-369.

MacLean, A., Young, R., Bellotti, V., \& Moran, T. (1991). Questions, options, and criteria: Elements of design space analysis. Human-Computer Interaction, 6, 201-250.

McCrickard, D. S., Chewar, C. M., Somervell, J. P., \& Ndiwalana, A. (2003). A model for notification systems evaluation: Assessing user goals for multitasking activity. Transactions on Computer-Human Interaction, 10, 312-338.

Michalko, M. (2006). Thinkertoys. Berkeley, CA, USA: Ten Speed Press.

Mumford, M. D. (2000). Managing creative people: Strategies and tactics for innovation. Human Resource Management Review, 10, 313-351.

Nathan, L., Friedman, B., \& Hendry, D. (2009). Sustainably ours: Information system design as catalyst: Human action and environmental sustainability. interactions, 16(4), 6-11.

Newman, M., Lin, J., Hong, J., \& Landay, J. A. (2003). DENIM: An informal web site design tool inspired by observations of practice. Human-Computer Interaction, 18, 259-324.

Osborn, A. F. (1963). Applied imagination: Principles and procedures of creative thinking. New York: Scribner.

Payne, C., Allgood, C. F., Chewar, C. M., Holbrook, C., \& McCrickard, D. S. (2003). Generalizing interface design knowledge: Lessons learned from developing a claims library. In Proceedings of the International Conference on Information Reuse and Integration (pp. 362-369). Washington, DC, USA: IEEE Computer Society.

Rittel, H. W. J., \& Webber, M. M. (1973). Dilemmas in a general theory of planning. Policy Sciences, 4, $155-169$.

Rosson, M. B., \& Carroll, J. M. (2002). Usability engineering: Scenario-based development of human-computer interaction. San Francisco: Morgan Kaufmann.

Saponas, T. S., Prabaker, M. K., Abowd, G. D., \& Landay, J. A. (2006). The impact of pre-patterns on the design of digital home applications. In Proceedings of the Conference on Designing Interactive Systems (pp. 189-198). New York: ACM Press.

Sharp, H., Rogers, Y., \& Preece, J. (2007). Interaction design: Beyond human-computer interaction. West Sussex, England: John Wiley \& Sons.

Shneiderman, B. (2000). Creating creativity: User interfaces for supporting innovation. Transactions on Computer-Human Interaction, 7, 114-138.

Simon, H. A. (1996). The sciences of the artificial ( $3^{\text {rd }}$ ed.). Cambridge, MA, USA: MIT Press.

Smith, S. (2009, May 1). Mobile + Social + Future: M4Change DC [Web log post]. Retrieved from http://www.changeist.com/changeism/2009/5/1/mobile-social-future-m4change-dc.html

Sonnenburg, S. (2004). Creativity in communication: A theoretical framework for collaborative product creation. Creativity \& Innovation Management, 13, 254-262.

Sutcliffe, A. G., \& Carroll, J. M. (2000). Designing claims for reuse in interactive systems design. International Journal of Human-Computer Studies, 50, 213-241.

Thomas, J. C., Lee, A., \& Danis, C. (2002). Creativity and interface: Enhancing creative design via software tools. Communications of the ACM, 45(10), 112-115.

Truong, K. N., Hayes, G. R., \& Abowd, G. D. (2006). Storyboarding: An empirical determination of best practices and effective guidelines. In Proceedings of the Conference on Designing Interactive Systems (pp. 12-21). New York: ACM Press.

van Duyne, D. K, Landay, J. A., \& Hong, J. I. (2007). The design of sites: Patterns for creating winning web sites. Upper Saddle River, NJ, USA: Prentice Hall.

von Oech, R. (2008). A whack on the side of the head. New York: Hachette Book Group. 
Wahid, S., Branham, S. M., Cairco, L., McCrickard, D. S., \& Harrison, S. (2009). Picking up artifacts: Storyboarding as a gateway to reuse. In Proceedings of the IFIP TC.13 Conference on Human-Computer Interaction (pp. 528-541). New York: Springer.

Wallas, G. (1926). The art of thought. New York: Harcourt, Brace \& World.

Wania, C. (2008). Examining the impact of an information retrieval pattern language on the design of information retrieval interfaces. Unpublished doctoral dissertation, Drexel University, Philadelphia, PA, USA.

Whittaker, S., Terveen, L., \& Nardi, B. A. (2000). Let's stop pushing the envelope and start addressing it: A reference task agenda for HCI. Human-Computer Interaction, 15, 75-106.

Wright, A. (2007). Glut: Mastering information through the ages. Ithica, NY, USA: Cornell University Press

Yahoo! Developer Network (n.d.). Design pattern library. Retrieved August 4, 2011, from http://developer.yahoo.com/ypatterns

\section{Authors' Note}

All correspondence should be addressed to

D. Scott McCrickard

Virginia Tech

Department of Computer Science

2202 Kraft Dr.

Blacksburg, VA, 24060

mccricks@cs.vt.edu

Human Technology: An Interdisciplinary Journal on Humans in ICT Environments

ISSN 1795-6889

www.humantechnology.jyu.fi 